\title{
The Impact of Applying Blockchain Technology on the Health Industry Especially in the Field of Health Oriented Products
}

\section{Mirshamsi F* \\ Master of Information Technology Management, Esfahan Sheikhbahaee University, Iran}

*Corresponding author: Farzad Mirshamsi, Master of Information Technology Management, Esfahan Sheikhbahaee University, Iran, Email: mirshamsi.farzad@gmail.com

\section{Research Article}

Volume 4 Issue 2

Received Date: March 30, 2020

Published Date: April 30, 2020

DOI: $10.23880 /$ nhij-16000220

\section{Abstract}

Nowadays, the health industry is one of the largest industries in the world, which includes more than $10 \%$ of gross domestic product in developed countries. Health industry consists of patient information management subsets, pharmaceutical and biomedical research, prescription and drug use management, medical records and test results, telemedicine, claim and payment of health insurance, supply chain management agent set, production, marketing, distribution, Sales, communication with stakeholders, internal and external commerce, monitoring and tracking of health-oriented products, especially human medicine. The many challenges that disrupt the effective processes in healthcare operational cycles have been identified and analyzed in this paper, to identify the impact of applying emerging blockchain technology solutions and their benefits, especially in health-centric businesses. Increasing growth of information technology science and its applications, especially the emergence and penetration of blockchain technology, not only have benefits for production, sales, support and supervision of health-oriented products, especially human-based medicines, but also can transform information and communication infrastructures, blockchain-based systems, capabilities, accuracy, speed and trust in health industry systems and in the supply of raw materials and requirements, marketing, sales, customer relationship management, Standards, Requirements and Supervisory Levels Drugs in organizations, companies and individuals involved in this industry with creating new business models, the annoying challenges will be fixed then the health industry of the world will transform.

Keywords: Blockchain Technology; Health Industry; Health Oriented Product

\section{Introduction}

Integration into the coding system for pharmaceuticals and medical equipment improves the conditions for systems communication and information exchange. Interoperability in health care has traditionally focused on data exchange between commercial entities. The transition from patientcentered to patient-centered performance in the healthcare industry is an exciting trend in healthcare, with blockchain technology having the potential to change the attitude, policy and ownership of clinical data exchange in the healthcare industry. Fundamentally change [1].

The World Economic Forum considers blockchain one of the most likely mega-trends to shape the world in the coming decade [2]. Blockchain can be applied to the supply chain to know who does what. In addition, the timing and location of these actions can be determined. Suppliers in the chain can also view transportation, delivery and work routines. In this way, blockchain builds trust between providers. Removing intermediary auditors can increase returns and reduce costs [3].

The Internet is connecting the world to thriving new business models based on Internet businesses, while blockchain will help solve the problem of trust using networked processing. Blockchain is poised to be a more exciting invention of the Internet [4]. 
In the business and business environment of healthcentered goods, individuals, organizations, companies, organizations, trade unions, associations, pharmacies and eventually the Food and Drug Administration operate under the Ministry of Health and Medical Education. Certainly, existing challenges, including the existence of maladaptive data and systems, incomplete, inconsistent and incomplete information, complex and non-expansive processes, difficult and inflexible management, weaknesses, and many threats. On the other hand, the Food and Drug Administration seeks to provide the most reliable and up-to-date resources and information and use of information technology to provide maximum assurance about the safety and health of food, pharmaceuticals, cosmetics and health by improving the performance of its regulatory systems and using Improve and accelerate the performance of electronic systems and the integration of databases from manufacturing units, supply centers, pharmacies, and testing registries. It will also make it easier, more reliable and effective to monitor and control the performance of private companies, technical authorities, pharmacies, and service providers in general [5].

Smart contracts are computer programs that run automatically according to the conditions set by the programmer and help us to exchange our valuable assets in a transparent process [6]. Smart contract is a new tool and method that simplifies the transaction process involving financial transactions [7].

Today, countries need to lay down its pillars in their legal systems to implement smart contracts. The pillars of smart contracts are encrypted currencies, blockchain, digital signatures and artificial intelligence [8].

In today's world, the economies with the power of technology have become more globalized. In fact, technology provides the outcomes that impact on competitive performance, some of which are: cost reduction, quality, timely delivery, and flexibility [9].

\section{Importance and Value of Research}

In the field of healthcare, the great transformation will happen soon. Systems store patient information, systems, drug information, systems, therapeutic and surgical, systems treated, systems, telemedicine, systems, walk nurse, robotic surgery systems, admission and many others including the future development of the health system worldwide behind new water mobility, a driving force of the storm surge [10].

In the pharmaceutical industry, blockchain is an essential technology to prevent counterfeiting and distribution of non-standard drugs by controlling the production, supply and sales chain. It also improves the quality of life by sharing patients' clinical information, R\&D status, health care and ultimately quality of life [11].

By identifying the hotspots and challenges in the healthoriented business of health oriented goods and services and taking advantage of opportunities and identifying the threats to IT performance with the blockchain technology approach in health industry, many benefits such as fast and secure communication with transparent, complete data delivery, Accurate and reliable are provided, as a result, Conditions and appropriate decision-making tools at the top management level of companies, affiliated and ministry-level organizations, improving productivity indicators, assisting in strategic planning and agility of organizations, institutions and even at national level will be created (Figure 1).

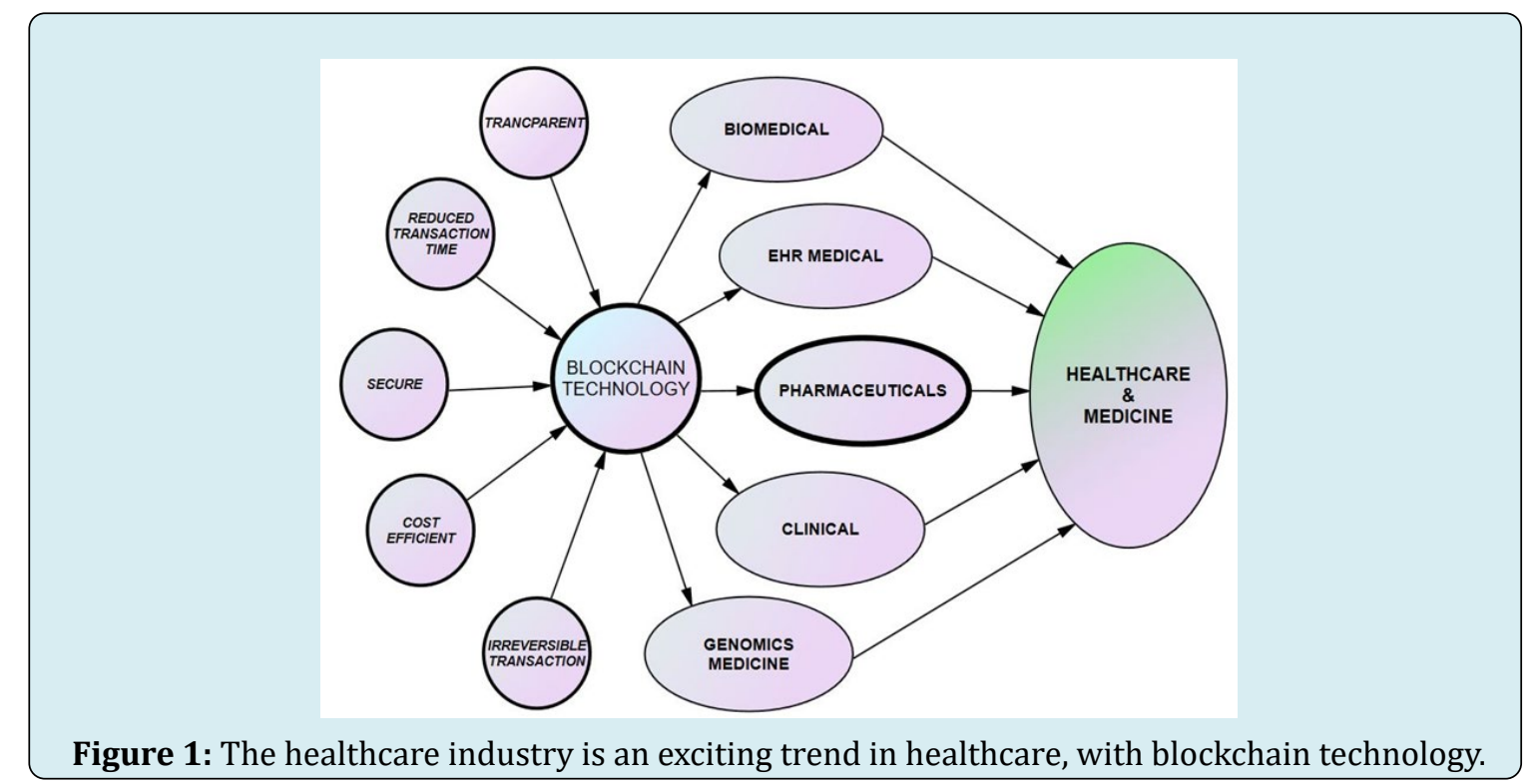

Mirshamsi F. The Impact of Applying Blockchain Technology on the Health Industry Especially in the Field of Health Oriented Products. Nurs Health Care Int J 2020, 4(2): 000220. 


\section{Conclusion}

The idea of using standard coding based on blockchain for commodities and products reinforces the exchange of information and transaction-related systems and systems related to the health industry, resulting in the integration of integrated information into regulatory and decisionmaking layers. Making it possible will improve the speed and quality of planning, policy and decision making at the highest organizational, national and global levels.

Results obtained using blockchain technology to improve the current performance of the health-oriented tracking and monitoring process, identifying products, counterfeit and contraband prevention, recording and reviewing the history of sensitive goods, products and materials for quality review and monitoring. Tracking will be very effective during the warehousing, shipping and distribution in the supply chain and ultimately improving the quality of life and human health.

The results will provide a dramatic shift in quality, quantity and timing for medical research and drug development results, early detection, disease prevention and improvement of the treatment process.

Due to the blockchain technology approach to Internet and global communications, the results of the research have adopted and applied blockchain technology at different levels of the health business, with fundamental changes in the style of trading, the use of currency codes, smart contracts, and the elimination of intermediaries. Commerce, and in particular the ability to connect to world trade, will enhance export of health-oriented products and transcend existing restrictions and sanctions for our beloved country.

The results can save a great deal of time and money, dramatically reduce medical errors and increase the effectiveness of health services and healthcare, and improve the processes and communications required by the ESS.

In general, the results of this research can be applied to all manufacturing units, distribution centers, pharmacies, Food and Drug Administration, and all components of the health-care-based business enterprise in our beloved country of Iran and even internationally.

\section{References}

1. Gordon WJ, Catalini C (2018) Blockchain technology for healthcare: facilitating the transition to patient-driven interoperability. Comput Struct Biotechnol J 16: 224230.

2. Hosseinpour H (2017) Application of Blockchain Ecosystem (Block Chain Extension) to Achieve Key Management Objectives and Supply Chain Structure. Master thesis. Mehr Astan Institute of Higher Education, Guilan.

3. Hayati A (2018) Blockchain's Role in Fulfilling the Key Goals of Supply Chain Management Case Study: Corporate Payments. Master thesis. Shahid Beheshti University, Tehran.

4. Jalali M (2017) Presentation of Blockchain Model in Internet Businesses Based on IoT. Master thesis. Basir Abik Institute of Higher Education, Qazvin.

5. Taftizadeh A (2018) Evaluation of Information Technology Functions in Yazd Food Dept. Using Fuzzy SWOT Approach. MA Thesis. University of Science and Art, Yazd.

6. Qaderi Sh (2018) Providing a security model for authentication using China Block. Master thesis. AlZahra University (Tehran).

7. Ghorbanian R (1397) Smart contract security. Master thesis. Mehr Astan Institute of Higher Education, Guilan.

8. Nasser M (1397) Feasibility of applying smart contracts in Iranian law. Master thesis. University of Forensic Sciences and Administrative Services, Tehran.

9. Bayat M (2014) Effective Factors in Technology of Drug Manufacturing. MA Thesis. Azad University, Tehran.

10. Farahmandian V, Farahmandian M, Mehrani Far A (2014) The Role of Information and Communication Technology in Iranian Health Management with a Future Look. Health Monthly 3(10): 21-38.

11. Siyal A, Junejo A, Zawish M, Ahmed K, Khalil A, et al. (2019) Applications of Blockchain Technology in Medicine and Healthcare: Challenges and Future Perspectives. Cryptography 3(1): 3. 